\title{
A Retrospective Evaluation of Cutaneous Adverse Drug Reactions (CADRs) Due to Antibiotics Using Naranjo Adverse Drug Reactions (ADRs) Probability Scale
}

\author{
Mohammed Helmy Faris Shalayel ${ }^{* 1}$, letimad Abdelsalam Mohamed Ayed ${ }^{2}$, Mohammed Ayed Huneif ${ }^{3}$, Yousif Mohammed Kordofani ${ }^{4}$ \\ 'Professor of Biochemistry and Specialist of Dermatology and Venereology, Najran University, KSA. \\ 2Pharmacology Department, Faculty of Medicine and Health Sciences, Omdurman Islamic University, SUDAN. \\ ${ }^{3}$ Department of Pediatrics, College of Medicine, Najran University, Najran, SAUDI ARABIA. \\ ${ }^{4}$ Professor of Dermatology, University of Bahri, Khartoum, SUDAN.
}

\begin{abstract}
Cutaneous adverse drug reactions (CADRs) have been found to be one of the most common adverse drug reactions (ADRs) in many studies. There is no common globally accepted tool for causality grading of ADRs to be utilized in pharmacovigilance programs. Our study aimed to show the coincidence of Naranjo method in evaluating clinically diagnosed cutaneous adverse drug reactions in Sudanese patients. The causality of the CADRs was retrospectively evaluated by using Naranjo's ADR probability scale. The study included 13 males (31.7\%) and 28 females (68.3\%). Of patients included in the study, 35 patients $(85.4 \%)$ had past history of drug reactions while only 6 ones (14.6\%) did not have. Scores of Naranjo algorithm ranged between 3 and 8 . There was a moderate agreement between clinically diagnosed CADRs and Naranjo algorithm. 8 cases (19.51\%) were assessed as 'possible' and 33 cases were assessed as 'probable' (80.49\%). It was concluded that although CADRs is much more easily to
\end{abstract}

be diagnosed clinically by dermatologists than other types of ADRs, it is worthy to apply this simple algorithm in dermatology centers so as not to misdiagnose some cases with simple skin eruptions and to make a more thematic decision on causality.

Key words: Cutaneous Adverse Drug Reactions (CADRs), Adverse Drug Reactions (ADRs), Naranjo Algorithm, Antibiotics.

Correspondence

Mohammed Helmy Faris Shalayel, Professor of Biochemistry and Specialist of Dermatology and Venereology, Najran University, KSA

Phone: 00966541476862

Email:drmhfs@hotmail.com

DOI: 10.5530/jyp.2018.10.25

\section{INTRODUCTION}

Causality assessment evaluates relationship between a drug treatment and the occurrence of an adverse event and establishes or declines the same. It is an important procedure which is used in pharmacovigilance programs for assessing suspected ADR reports for evaluation of the drugs' safety for use and for regulatory targets as well. ${ }^{1}$

The major source of information in pharmacovigilance is regional or country-wide system reporting of suspected adverse drug reactions. Naranjo algorithm or WHO probability Scale are adopted based on the consensus of the causality assessment committee involved. However, in case of analysis of serious ADRs, both scales should be utilized to assist in confirming the case. ${ }^{2}$

Cutaneous adverse drug reactions (CADRs) have been found to be one of the most common adverse drug reactions (ADRs) in various studies. ${ }^{3,4}$ Adverse cutaneous drug reactions are recognized as being major health problems worldwide causing significant costs for health care systems. ${ }^{5}$ It is an undesirable change in the structure, function, appendages of the skin or mucous membranes and comprises all adverse events related to drug eruption. ${ }^{6}$ Moreover, it is responsible for approximately $2-3 \%$ of all disabling injuries during hospitalization ${ }^{7}$ reaching to $6.7 \%$ in some studies. ${ }^{8,9}$ Many of the commonly used drugs have reaction rates over $1 \%$. The pattern of cutaneous adverse drug eruptions and the offending drugs responsible for them keep changing every year. ${ }^{10,11}$

There is a wide spectrum of cutaneous adverse drug reactions. These include, drug reaction with eosinophilia and systemic symptoms (DRESS), Stevens-Johnson syndrome (SJS), toxic epidermal necrolysis
(TEN) and acute generalized exanthemata's pustulosis (AGEP). ${ }^{5}$ Drug eruptions range from transient erythema to the life threatening severe cutaneous adverse reactions (SCAR) that encompass Stevens-Johnson syndrome (SJS), toxic epidermal necrolysis (TEN), acute generalized exanthematous pustulosis (AGEP) and drug reaction with eosinophilia and systemic symptoms complex (DRESS).

Our study aimed to show the accuracy of Naranjo method in evaluating clinically diagnosed cutaneous adverse drug reactions in Sudanese patients attended Khartoum Dermatology and Venereal Diseases Teaching Hospital - Sudan.

\section{PATIENTS AND METHODOLOGY}

This was a retrospective descriptive study. The data were obtained from Sudanese patients who previously diagnosed as CADRs due to antibiotics during the period from October 2015 to April 2016 in Khartoum Dermatology and Venereal diseases Teaching Hospital - Sudan. It was conducted after receiving written consent from patients and approval from Animal and Human Ethical Committee of Omdurman Islamic University. All procedures followed were in accordance with the ethical standards of the responsible committee on human experimentation (institutional and national) and with the Helsinki Declaration of 1975, as revised in Brazil 2013.

The causality of the CADRs was evaluated by using Naranjo's ADR probability scale. The Naranjo's ADR probability scale evaluates the causality 
of the ADRs and categorizes them as Definite, Probable, Possible and Doubtful (Table 1) $)^{12,13}$

Data from 41 patients, who previously diagnosed as CADR, were evaluated to fit the category of probable or possible drug reaction as per Naranjo ADR probability scale. Records of preliminary information, detailed history regarding presenting symptoms, intensity and duration, and other symptoms if any were elicited and considered. Also, thorough drug history was reviewed regarding history of implicated drugs that may cause cutaneous drug reaction like antibiotics, opioids, NSAIDs, corticosteroids, antiepileptic and other drugs. Patients with cutaneous drug reaction due to medications other than antibiotics were excluded from the study. A thorough dermatological examination regarding the clinical pattern of the lesions was deemed as well. Thirty- eight patients were clinically diagnosed as confirmed CADR while 3 ones were doubtfully diagnosed as CADR and were wholly treated according to the time of visit after appearance of skin lesions.

The data were analyzed using SPSS (Statistical Package for the Social Sciences) and descriptively summarized using frequencies and percentages. Cohen's Kappa index value was calculated to measure the agreement between those who clinically diagnosed as CADR and probable ADR estimated by Naranjo algorithm.

Drug eruptions range from transient erythema to the life threatening severe cutaneous adverse reactions (SCAR) that encompass StevensJohnson syndrome (SIS), toxic epidermal necrolysis (TEN), acute generalized exanthematous pustulosis (AGEP) and drug reaction with eosinophilia and systemic symptoms complex (DRESS).

Drug eruptions range from transient erythema to the life threatening severe cutaneous adverse reactions (SCAR) that encompass Stevens-Johnson syndrome (SJS), toxic epidermal necrolysis (TEN), acute generalized exanthematous pustulosis (AGEP) and drug reaction with eosinophilia and systemic symptoms complex (DRESS).

\section{RESULTS}

The study included 13 males (31.7\%) and 28 females (68.3\%). Of patients included in the study, 35 patients $(85.4 \%)$ had past history of drug reactions while only 6 ones (14.6\%) did not have. Scores of Naranjo algorithm ranged between 3 and 8 (Table 2).

Our result revealed that most of cases (33 out of 41 patients, $80.49 \%$ ) assigned causality category of "probable" with Naranjo scale.

Cohen's kappa coefficient (Cohen's Unweighted Kappa) was 0.941 with $95 \%$ confidence interval $=0.492(0.132,0.851)$ indicating a moderate agreement between clinically diagnosed CADRs and Naranjo algorithm (Table 3)

\section{DISCUSSION}

Almost all the drugs utilized for therapeutic benefits are associated with inescapable risks of adverse drug reactions, varying from very minor to exceedingly severe and infrequently fatal wayward influence. ${ }^{14}$ Hence, Reporting of ADRs after drug marketing should be actively motivated and should encompass all those concerned including doctors, nurses, patients, pharmacists and pharmaceutical companies. ${ }^{15}$

Although algorithms have better reproducibility than clinical judgment in rating ADRs, clinical judgment with its low inter- and intra-rater agreement still plays an important role in the identification and rating of potential ADRs by an algorithm. This is because the response to some of the questions in the algorithm may be influenced by clinical judgment. More significantly the initiative step in ADR recognition depends on a clinical judgment. ${ }^{16}$

Previous studies have shown that there are a lot of variations between rater and within rater decisions on causality of ADRs; this applies both to pharmacologists and physicians. ${ }^{17,18}$

Most of previous studies adopted two ADR causality assessment scales, the World Health Organization-Uppsala Monitoring Center (WHOUMC) and Naranjo scales. Belhekar et al. ${ }^{18}$ Showed in their study that the most common causality category using the WHO-UMC criteria as well as the Naranjo algorithm was "possible" and disagreement was found among the two scales $(4.9 \% ; \kappa=0.145)$. Their disagreement percentage was lower that found by other previous studies. ${ }^{19,20}$ Since several studies accept the categorization of possible or greater as an ADR, then perhaps clinicians artlessly need to comprehend how can these algorithms be implemented at assessing ADRs. ${ }^{21,22}$ Thus, expert judgment is typically based on the decisive factor on which algorithms are based so there is a need to develop a high quality assessment method which can accurately set up suitable diagnostic criteria for ADRs. ${ }^{23}$ Although Naranjo scale is easily applied, yet in case reports or series of overdose patients, the Naranjo Scale has been stratified to evaluate the probability an event was caused by the ingested drug or therapeutic modality. This application of the Naranjo Scale is not scientifically valid and may lead to faulty derivations. ${ }^{24}$

The most abundantly applied algorithms for casuality assessment are the Naranjo algorithm, ${ }^{13}$ WHO-UMC, ${ }^{18-25}$ the Jones' algorithm, ${ }^{26}$ the Karch algorithm, ${ }^{27}$ RUCAM algorithm, ${ }^{28}$ the Begaud algorithm, ${ }^{29}$ the French algorithm, ${ }^{30}$ the ADRAC, ${ }^{31}$ and the Korean algorithm. ${ }^{32}$ These algorithms

\begin{tabular}{|c|c|c|c|}
\hline Yes & No & Do Not Know & Score \\
\hline+1 & 0 & 0 & \\
\hline+1 & 0 & 0 & \\
\hline+2 & -1 & 0 & \\
\hline+1 & 0 & 0 & \\
\hline+1 & 0 & 0 & \\
\hline+1 & 0 & 0 & \\
\hline+1 & 0 & 0 & \\
\hline
\end{tabular}

Scoring of Naranjo algorithm: $>9$ = definite ADR; 5-8 = probable ADR; $1-4=$ possible ADR; $0=$ doubtful ADR

Total Score: Adapted from Naranjo et al. . $^{12}$ 


\begin{tabular}{lccc} 
Table 2: Naranjo score for patients with CADRs due to antibiotics & & \\
\hline \multicolumn{1}{c}{ Offending antibiotics } & Number of cases & Diagnosis & Naranjo score \\
\hline Ciprofloxacin & 17 & Fixed drug eruption, EM-major, SJS, TEN & $5-6$ \\
Artisunate & 5 & EM-major, SJS, TEN & $6-8$ \\
Penicillins & 3 & EM-major, SJS & 5 \\
Sulfamethoxazole -Trimethoprim (cotrimoxazole) or Seprtin & 3 & SJS, TEN, SJS/TEN overlap \\
Norfloxacin & 3 & TEN & 4 \\
Amoxicillin & 2 & SJS, TEN & 8 \\
Ceftriaxone & 2 & SJS, TEN & 8 \\
Ampiclox (Ampicillin/Cloxacillin) & 1 & SJS \\
Amoclan (Amoxicillin/Clavulenic acid) & 1 & EM-major \\
Fansidar (sulfadoxine and pyrimethamine) & 1 & SJS \\
Erythromycin & 1 & EM-major \\
Clarithromycin & 1 & TEN \\
Tetracycline & 1 & SJS/TEN overlap \\
\hline
\end{tabular}

\begin{tabular}{|c|c|c|c|}
\hline \multirow{2}{*}{$\frac{\text { Observed Kappa }}{0.491}$} & \multirow[t]{2}{*}{ Standard Error } & \multicolumn{2}{|c|}{$0.95 \%$ Confidence Interval } \\
\hline & & Lower limit & Upper limit \\
\hline Clinically diagnosed CARD & 0.213 & 0.074 & 0.909 \\
\hline Naranjo Algorithm & 0.184 & 0.132 & 0.851 \\
\hline
\end{tabular}

are used in different countries with different genetic backgrounds, investigators, and level of awareness for ADRs. ${ }^{33}$ The Naranjo algorithm is advantageous in being quite simple to be applied and its assessment is possible even with little knowledge and experience. ${ }^{32}$ Nevertheless, the Naranjo algorithm contains many components that are not suitable for clinical assessment for ADRs like assessment for the response after administering a placebo that actually had not been done (question 6) and a non-coherent question (question 10), which may cause variations between different judging clinicians. ${ }^{33,34}$

Our results revealed that there is a moderate agreement between clinically diagnosed CADRs and Naranjo algorithm. 8 cases (19.51\%) were assessed as 'possible' and 33 cases were assessed as 'probable' (80.49\%) in the current study.

To the best of our knowledge, it is the first study in Sudan tried to evaluate causality of the CADRs by using Naranjo's ADR probability scale. Although CADRs is much more easily to be diagnosed clinically by dermatologists than other types of ADRs, it is worthy to apply this simple algorithm in dermatology centers so as not to misdiagnose some cases with simple skin eruptions and to make a more thematic decision on causality.

\section{CONFLICT OF INTEREST}

None declared.

\section{AUTHOR CONTRIBUTIONS}

MHFS: concept and design of the study, clinical studies, analysis and interpretation, manuscript preparation, critical and final revision of the manuscript and literature search. IAMA: concept and design of the study, data collection, and literature search. MHA: data collection, clinical studies, data acquisition, statistical analysis. YMK: concept and design of the study, supervision of the study.

\section{ABBREVIATIONS USED}

ADRAC: Australian Adverse Drug Reaction Advisory Committee; ADRs: Adverse Drug Reactions; CADRs: Cutaneous Adverse Drug Reactions; DRESS: Drug Reaction with Eosinophilia and Systemic Symptoms; NSAIDs: Non-Steroidal Anti Inflammatory Drugs; RUCAM: Roussel UCLAF Causality Assessment Method; SJS: StevensJohnson syndrome; TEN: Toxic Epidermal Necrolysis; WHO-UMC: World Health Organization-Uppsala Monitoring Center.

\section{REFERENCES}

1. Sadhotra A, Gupta A, Walia R, Sharma N. Mechanisms, Methods of Detection and Causality Assessment of Adverse Drug Reactions. Indian J Pharm Pharmacol. 2016;3(1);29-32

2. Pharmacovigilance guide for adverse drug reaction monitoring and causality assessment, 2015. Available at: http://dra.gov.bt/wp-content/uploads/2016/05/ Pharmacovigilance-guideline.pdf.

3. Svensson CK, Cowen EW, Gaspari AA. Cutaneous drug reactions. Pharmacol Rev. 2001;53:357-79.

4. Sharma R., Dogra D, Dogra N. A study of cutaneous adverse drug reactions at a tertiary center in Jammu, India. Indian Dermatol Online J. 2015;6(3):168-171. doi: 10.4103/2229-5178.156384.

5. Hoetzenecker W, Nägeli M, Mehra ET, Jensen AN, Saulite I, Schmid-Grendel-

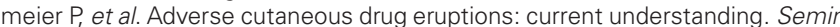
Immunopathol 2016;38(1):75-86. doi: 10.1007/s00281-015-0540-2.

6. Nayak S, Acharjya B. Adverse cutaneous drug reaction. Indian J Dermato/ 2008 53(1):2-8. http://dx.doi.org/10.4103/0019-5154.39732.

7. Pourpak Z, Fazlollahi MR, Fattahi F. Understanding adverse drug reactions and drug allergies: principles, diagnosis and treatment aspects. Recent Pat Inflamm Allergy Drug Discov. 2008;2(1):24-46.

8. Bond CA, Raehl CL. Adverse drug reactions in United States hospitals. Pharmacotherapy 2006;26(5):601-8.

9. Zhan C, Arispe I, Kelley E, Ding T, Burt CW, Shinogle J. Ambulatory care visits for treating adverse drug effects in the United States, 1995-2001. Jt Comm J Qual Patient Saf 2005;31(7):372-8.

10. Pudukadan D, Thappa DM. Adverse cutaneous drug reactions: Clinical pattern and causative agents in a tertiary care center in South India. Indian J DermatolVenereolLeprol 2004;70:20-24. 
11. Sharma VK, Sethuraman G, Kumar B. Cutaneous adverse drug reactions: Clinical pattern and causative agents-A six-year series from Chandigarh, India. J Postgrad Med 2001;47:95-9.

12. Naranjo CA, Busto U, Sellers EM, Sandor P, Ruiz I, Roberts EA. A method for estimating the probability of adverse drug reactions. Clin Pharmacol Ther 1981;30(2):239-45.

13. Zaki SA. Adverse drug reaction and casuality assessment scales. Lung India $2011 ; 28(2): 152-53$

14. Curtin F., Schulz P. Assessing the benefit: risk ratio of a drug —randomized and naturalistic evidence. Dialog Clin Neurosci. 2011;13(2):183-90.

15. Sadhotra A, Gupta A, Walia R. Sharma N. Mechanisms, Methods of Detection and Causality Assessment of Adverse Drug Reactions. Indian J Pharm Pharmacol. 2016;3(1);29-32.

16. Doherty MJ. Algorithms for assessing the probability of an Adverse Drug Reaction. Respir Med. 2009;2(2):63-67.

17. Blanc S, Leuenberger P, Berger JP, Brooke EM, Schelling JL. Judgements of trained observers on adverse drug reactions. Clin Pharmacol Ther. 1979; 25:493-8.

18. Belhekar MN, Taur SR, Munshi RP. A study of agreement between the Naranjo algorithm and WHO-UMC criteria for causality assessment of adverse drug reactions. Indian J Pharmacol. 2014;46:117-20.

19. Rehan HS, Chopra D, Kakkar AK. Causality assessment of spontaneously reported adverse drug events: Comparison of WHO-UMC criteria and Naranjo probability scale. Int J Risk Saf Med. 2007;19(4):223-7.

20. Son MK, Lee YW, Jung HY, Yi SW, Lee KH, Kim SU, et al. Comparison of the Naranjo and WHO-Uppsala Monitoring Centre criteria for causality assessment of adverse drug reactions. Korean J Med. 2008;74(2):181-7.

21. Kane-Gill SL, Visweswaran S, Saul MI, Wong AK, Penrod LE, Handler SM. Computerized detection of adverse drug reactions in the medical intensive care unit. Int J Med Inform. 2011;80(8):570-8.

22. Kane-Gill SL, Forsberg EA, Verrico MM, Handler SM. Comparison of Three
Pharmacovigilance Algorithms in the ICU Setting. Drug Saf. 2012;35(8):645-53.

23. Khan LM, Al-Harthi SE, Osman AM, Sattar MA, Ali AS. Dilemmas of the causality assessment tools in the diagnosis of adverse drug reactions. Saudi Pharm J. 2016; 24(4):485-93. doi: 10.1016/j.jsps.2015.01.010. Review.

24. Seger D, Barker K, McNaughton C. Misuse of the Naranjo adverse drug reaction probability scale in toxicology. Clin Toxicol. 2013;51(6):461-6.

25. WHO-UMC causality assessment system. Available from: http://www.whoumc.org/pdfs/Causality.pdf.

26. Jones JK. Adverse drug reactions in the community health setting; approaches to recognizing, counseling and reporting. Fam. Community Health 1982;5(2):58-67.

27. Karch FE, Lasagna L. Towards the operational identification of adverse drug reaction. Clin Pharmacol Ther 1977;21(3):247-54.

28. Danan G, Benichou C. Causality assessment of adverse reactions to drugs--I. A novel method based on the conclusions of international consensus meetings: application to drug-induced liver injuries. J Clin Epidemio/1993;46(11):1323-30.

29. Begaud B, Evreux JC, Jouglard J, Lagier G. Imputation of the unexpected or toxic effects of drugs. Actualisation of the methods used in France. Therapie 1985;40(2):115-8.

30. Moore N, Paux G, Begaud B, Biour M, Loupi E, Boismare F, et al. Adverse drug reaction monitoring: doing it the French way. The Lancet. 1985;326(8463):1056-8.

31. Mashford MI. The Australian method of drug event assessment. Drug Inf J 1984;18(3-4):271-3.

32. Hong KS, Park BJ, Sin SG, Yang JS, Lee SM, Kim YN, et al. Development of a Korean algorithm for causality assessment of adverse drug reactions. J Korean Soc Clin Pharmacol Ther 2002;10:129-42.

33. Young-Min Son, Jong-Rok Lee, Joo-Young Roh. Causality Assessment of Cutaneous Adverse Drug Reactions. Ann Dermatol 2011; 23(4): 432-438. doi: 10.5021/ad.2011.23.4.432.

34. Lee SM, Hahn SK, Park BJ. Signal detection and causality evaluation for pharmacovigilance. J Korean Soc Clin Pharmacol Ther. 2005;13:121-33.

Article History: Submission Date : 10-04-2017 ; Revised Date : 23-05-2017; Acceptance Date : 18-06-2017.

Cite this article: Shalayel MHF, Ayed IAM, Huneif MA, Kordofani YM. A Retrospective Evaluation of Cutaneous Adverse Drug Reactions (CADRs) Due to Antibiotics Using Naranjo Adverse Drug Reactions (ADRs) Probability Scale. J Young Pharm. 2018;10(1):113-6. 